\title{
Remote Working in the COVID-19 Pandemic: Results From a Questionnaire on the Perceived Noise Annoyance
}

\author{
Giuseppina Emma Puglisi *, Sonja Di Blasio, Louena Shtrepi and Arianna Astolfi \\ Department of Energy, Politecnico di Torino, Turin, Italy
}

Noisiness in the working environment was largely proved to have effects on the working activity and performance. To limit the spreading of the COVID-19 pandemic in the first wave between March and May 2020, Italian workers had massively started performing remote working. Insights on the subjective perception of noise annoyance under the remote working settings were thus necessary. Workers from a university and from several large and small Italian companies, resulting in 1,934 participants overall, answered to a questionnaire on the perception of noise annoyance in the remote working environment. $A$ total of $57 \%$ of the responding workers stated to be sensitive to noise. The questionnaire

Edited by:

Bin Yang,

Xi'an University of Architecture and

Technology, China

Reviewed by:

Yongzheng Yao,

China University of Mining and

Technology, Bejiing, China

Simone Torresin,

University of Trento, Italy

*Correspondence:

Giuseppina Emma Puglisi giuseppina.puglisi@polito.it

Specialty section:

This article was submitted to

Indoor Environment,

a section of the journal

Frontiers in Built Environment

Received: 30 March 2021

Accepted: 30 July 2021

Published: 14 September 2021

Citation:

Puglisi GE, Di Blasio S, Shtrepi L and Astolfi A (2021) Remote Working in the COVID-19 Pandemic: Results From a

Questionnaire on the Perceived

Noise Annoyance.

Front. Built Environ. 7:688484

doi: 10.3389/fbuil.2021.688484 was delivered online; data were recorded anonymously and then aggregated for statistical analyses. Results show that 55\% of the workers perform their activity in an isolated room of the home environment, $43 \%$ in a shared room (e.g., kitchen, living room), and $2 \%$ in an outdoor space, with the majority of workers (57\%) performing activity without other people in the environment. Among the noise sources investigated, $25 \%$ of workers recognize the noise generated by people (e.g., talking, moving, calling, listening to music) as the main source of disturbance. The negative consequences of noise annoyance during the remote working hours are mainly related to a loss of concentration and to a difficulty in relaxing. Furthermore, workers reported to get easily irritated by noise generated from the neighborhoods or from the housemates as it tends to distract from finishing a task.

Keywords: well-being, noise annoyance, office acoustics, remote working, noise sensitivity

\section{INTRODUCTION}

During the COVID-19 pandemic, Italian workers have been pushed to perform remote working to limit the increasing number of infections from the virus, especially within the first wave in MarchMay 2020, with a progressively growing portion of population working from home. According to a recent report from the Italian National Institute of Statistics (ISTAT-Istituto Nazionale di Statistica, 2020 ), remote working was engaged by $8 \%$ of microenterprises (i.e., with 3-9 workers), $19 \%$ of smallsize enterprises (i.e., 10-49 workers), 50\% of medium-size enterprises (i.e., 50-249 workers), $77 \%$ of large-size enterprises (i.e., more than 250 workers). Such a change in the working organization has thus brought a great number of people to live and work in the same location, that is, at home. Recent studies highlighted the quantity of positive aspects related to remote working, such as improved working performance, cutting of traveling costs, saving of time, and increasing of employee satisfaction (Barbuto et al., 2020; Thulin et al., 2020). From an acoustic point of view, an 
investigation approach based on indoor soundscape (Torresin et al., 2020a) revealed a number of positive effects on remote working and people's well-being. As an example, Torresin et al. (2021) reviewed a number of studies that proved the significant association between perceived soundscapes rated as positive and 1) a faster recovery from stress, 2) better self-reported health conditions, and 3) higher self-reported well-being. Furthermore, they found a positive and significant association between perceived well-being and comfortable-rated soundscapes from people who worked from home, particularly when a little component of "content" (i.e., so-defined as an empty or full of content continuum) was present in the environment. However, there are several detrimental effects on the perceived well-being related to the remote working condition. Several authors have shown the increase of stress, discomfort, and anxiety during the remote working, especially because of a continuous usage of technology (Tarafdar et al., 2010; Salanova et al., 2013; Molino et al., 2019) and of an increased sedentary behavior associated with longer sitting and screen time (McDowell et al., 2020). Furthermore, working from home involves different job routines alternated to family needs: frequent changes in the working process, and various cognitive tasks in turn, were proved to lead to additional negative effects such as a sense of frustration and feeling guilt (Spagnoli et al., 2020). In this framework, the features of a built environment may play a critical role in health. Amerio et al. (2020) reviewed several studies that proved the onset of mood lability, depressive and anxiety symptoms, alcohol abuse, irritability, in subjects who have experienced COVID-19 quarantine. In their study based on the administration of online surveys, they observed that a poor quality view from the inside to the outside of a house was associated with moderate and severe depressive symptoms, and that this combination of factors generated a significant loss in working performance. Andargie et al. (2021) observed in a study on Canadian remote workers that the problem of insulation from airborne sounds and impact noises in buildings was the major cause of annoyance during working hours.

Together with personal issues, effects on the working activity may be due to recurrent environmental conditions; however, the extent to which they act in the remote working setting is largely unexplored. Before the pandemic, in fact, studies have mainly focused on understanding how noise from neighbors could annoy dwellers, revealing that noise from neighboring flats is the second most relevant source of noise (32\% of answers) when staying at home (WHO-World Health Organization, 2007) right after traffic (38\% of answers). Therefore, it is reasonable to investigate on the effect of noises in the living environment once people are asked to stay at home also for working.

When working from a specific workplace, it is fundamental to recognize the noise sources that mainly cause disturbance and degrade productivity (D'Orazio et al., 2019). In shared and openplan offices the noise that is generated from colleagues who converse, laugh, or talk at the phone (i.e., the so-called irrelevant speech) was found to be one of the main causes of annoyance and reduced productivity, and of growing of symptoms related to mental health and well-being (Di Blasio et al., 2019). In addition, having a positive acoustic environment when working has consequences on the perceived comfort and well-being, in fact noisy offices may bring to frequent headaches (Pejtersen et al., 2006; Kaarlela-Tuomaala et al., 2009), loss of concentration (Banbury and Berry, 2005; Pejtersen et al., 2006; Kaarlela-Tuomaala et al., 2009) and motivation (Jahncke et al., 2011), general sense of stress (Evans and Johnson, 2000; WHOWorld Health Organization, 2000). Under such conditions, speech intelligibility, and so the ability of understanding words with a reduced involvement of cognitive resources, is strongly challenged too (Colle and Welsh, 1976; Hongisto et al., 2007; Haapakangas et al., 2014; Schlittmeier and Liebl, 2015; D’Orazio et al., 2018). As a remote working environment typically hosts a whole family or house-mates group, irrelevant speech can thus be considered one of the main causes of noise annoyance as it happens in proper workplaces. Nevertheless, understanding which are other recurrent and annoying noise sources may help practitioners in contributing to the acoustic design of homes also to support remote working premises.

Following an article by the authors that focused on the effects of irrelevant speech noise in offices of different sizes (Di Blasio et al., 2019), the aim of this work is to extend outcomes to the environments where remote working is performed as its practice is getting more and more common. The approach adopted in the present study may only partially represent the actual perception of indoor soundscapes during the remote working situation, as it does not account for the possible positive features related to the environment. However, the authors aimed at investigating the annoyance generated by noise from the very beginning. In particular, the aim of the present study is twofold: 1) to investigate the effects of noise on the perceived annoyance, productivity, mental health, and well-being; 2) to assess the relationship between noise annoyance, subjective and environmental characteristics.

\section{METHODOLOGY}

\section{Participants}

Workers were recruited via online questionnaire in May 2020. The overall response rate corresponded to $20 \%$, which is in agreement with other works that used the same method of online questionnaires administration (Nulty, 2008). Owing to incomplete answers, a final number of 1,934 respondents were considered who belonged to one university $(n=1,104)$, one large size company $(n=731), 25$ research and development units related to university $(n=59)$, five research centers $(n=10)$, and 19 small-size companies $(n=30)$.

The respondents' characterization with the description of the information related to the city where the remote working was experienced, age, gender, professional sectors, and number of people in the working environment and in the overall living environment too is provided in Table 1.

Concerning the remote working environment, respondents were grouped into five clusters based on the most recurrent typology of room/space where they were placed, that is, in a separate environment (e.g., a room where the worker could isolate herself or himself; $54.6 \%$ of the answers), in a shared environment 
TABLE 1 | Main characteristics of the total sample $(n=1934)$ given overall.

\begin{tabular}{|c|c|c|c|}
\hline \multicolumn{2}{|l|}{ Background information } & \multicolumn{2}{|c|}{ Overall } \\
\hline & & $\mathbf{n}$ & $\%$ \\
\hline \multirow[t]{2}{*}{ Gender } & Female & 1,127 & 58 \\
\hline & Male & 807 & 42 \\
\hline \multirow[t]{5}{*}{ Age range } & $18-25$ & 74 & 4 \\
\hline & $26-35$ & 509 & 26 \\
\hline & $26-50$ & 534 & 28 \\
\hline & $51-65$ & 783 & 40 \\
\hline & $65+$ & 34 & 2 \\
\hline \multirow[t]{2}{*}{ Nationality } & Italian & 1889 & 98 \\
\hline & Other & 45 & 2 \\
\hline \multirow[t]{4}{*}{ Remote working city } & Northern Italy & 1,560 & 81 \\
\hline & Central Italy & 122 & 6 \\
\hline & Southern Italy & 228 & 12 \\
\hline & Other & 24 & 1 \\
\hline \multirow[t]{11}{*}{ Professional sector } & Technical & 381 & 20 \\
\hline & Engineering & 490 & 25 \\
\hline & Management & 164 & 8 \\
\hline & Administration & 445 & 23 \\
\hline & Creative, design and architecture & 123 & 6 \\
\hline & Other & 80 & 4 \\
\hline & Teaching & 40 & 2 \\
\hline & Researcher & 97 & 5 \\
\hline & Sales and public affairs & 48 & 2 \\
\hline & Teaching and researcher & 37 & 2 \\
\hline & Services & 29 & 1 \\
\hline \multirow[t]{4}{*}{ Number of people in the remote working environment (yourself excluded) } & 0 & 1,100 & 57 \\
\hline & $1-2$ & 743 & 38 \\
\hline & $3-4$ & 85 & 4 \\
\hline & $5+$ & 6 & 0 \\
\hline \multirow[t]{4}{*}{ Number of people in the overall living environment (yourself excluded) } & 0 & 284 & 15 \\
\hline & $1-2$ & 1,061 & 55 \\
\hline & $3-4$ & 547 & 28 \\
\hline & $5+$ & 42 & 2 \\
\hline
\end{tabular}

(e.g., an open space, the kitchen, the living room; $43.1 \%$ of the answers), outdoor (e.g, a balcony, a terrace, a garden; $0.8 \%$ of the answers), other environments (1.1\% of the answers), a mix of the above (when they reported to change repeatedly the workstation in the house; $0.4 \%$ of the answers).

The location of the city in which the company/research center/ university were settled was asked as there can be sociocultural differences whether it is in the North or in the South of the country (Carboni and Russu, 2018). In the present work, however, the location of the city where the remote working activity was performed was considered, as sociocultural factors could also be mixed with geographical premises that led, for instance, to keep windows opened due to weather conditions that brought to an increased perception of noise from the outside rather than from the inside.

\section{Questionnaire}

The questionnaire was designed according to a previous work (Di Blasio et al., 2019). It was delivered online, and the participation was given on a voluntary base: an email was sent with a link that directed to the compilation of a Google Form approved by the head of the human resources of each company. The email was accompanied by an invitation letter with a brief explanation to inform the workers about the aim of the study, the confidential treatment of their personal data, and the anonymity of the answers.

An overall number of 22 questions with close answer were included in the questionnaire, which was delivered both in Italian and in English to reach the majority of workers possible. The compilation time was estimated in approximately 2 minutes, as questions were designed to be very easy to be read and the possible answers were either organized on a 5-point scale or on a single-choice selection.

Seven questions were related to the respondents' background about gender, age, nationality, company name, location of the city of the company, city of remote working, professional sector, and two more questions were asked with regards to the number of people in the working environment and in the overall living environment-excluding the respondent herself or himself-as already reported in 
TABLE 2 | Questionnaire layout.

\begin{tabular}{|c|c|c|c|c|}
\hline Topic & ID & Question & Scale & Label(s) \\
\hline Annoyance & Q1 & $\begin{array}{l}\text { How much does noise annoy you during your smart } \\
\text { working activity }\end{array}$ & 5 & Not at all (1) - Extremely (5) \\
\hline $\begin{array}{l}\text { Mental health well-being } \\
\text { (feelings and symptoms) }\end{array}$ & Q2 & $\begin{array}{l}\text { What is the main feeling (or symptom) related to noise } \\
\text { during your remote working activity }\end{array}$ & $\begin{array}{l}\text { Single } \\
\text { choice }\end{array}$ & $\begin{array}{l}\text { - Stress } \\
\text { - Negative feeling such as feeling displeased } \\
\text { - Negative feelings toward other housemates } \\
\text { - Loss of concentration } \\
\text { - Anger } \\
\text { - Loss of motivation } \\
\text { - Headache } \\
\text { - Tiredness and overstrain } \\
\text { - None } \\
\text { - Other }\end{array}$ \\
\hline
\end{tabular}

Work productivity
How much do you agree with the following statements?

Q3 Noise often interrupts me during my smart working activity

Q4 Noise does not allow me to work as much as I would like

5

Strongly disagree (1) - Strongly agree (5)

Q5 Noise significantly reduces my work performance during my remote working activity

\begin{tabular}{|c|c|c|c|c|}
\hline $\begin{array}{l}\text { Mental health well-being } \\
\text { (interpersonal relationships) }\end{array}$ & Q6 & $\begin{array}{l}\text { Noise during my remote working activity compromises } \\
\text { the harmony at home }\end{array}$ & 5 & Strongly disagree (1) - Strongly agree (5) \\
\hline $\begin{array}{l}\text { Occupants' behavior } \\
\text { (personal strategies) }\end{array}$ & Q7 & $\begin{array}{l}\text { What is the main strategy that you use to reduce the } \\
\text { annoyance resulting from noise during your remote } \\
\text { working activity? }\end{array}$ & $\begin{array}{l}\text { Single } \\
\text { choice }\end{array}$ & $\begin{array}{l}\text { - Take a break } \\
\text { - Change work task } \\
\text { - Headphones with music } \\
\text { - Noise cancelling headphones } \\
\text { - Open the window } \\
\text { - Close the window } \\
\text { - Change room } \\
\text { - Close the room door } \\
\text { - Plan the return to office } \\
\text { - Ask people to reduce their voice volume } \\
\text { - None } \\
\text { - Other }\end{array}$ \\
\hline
\end{tabular}

How much do you agree with the following statements?

Occupants' sensitivity and reaction to noise
Q8 I am sensitive to noise

Q9 I find it hard to relax in a place that is noisy

Q10 I get mad at people who make noise that keeps me from falling asleep or getting work done

Q11 I get annoyed when my neighbors are noisy

Q12 I get used to most noises without much difficulty

Noise source perception
Q13 What is the main source of noise present during your remote working activity?
$5 \quad$ Strongly disagree (1) - Strongly agree (5)

$\begin{array}{ll}\text { Single } & \text { - Technological noise (household appliances, systems, } \\ \text { choice } & \text { television, tablets) } \\ \text { - Traffic (vehicular, rail, air) } & \text { - Sirens (ambulances and firefighters) } \\ \text { - Anthropic noise generated by children under the age of } \\ & 5 \text { years, anthropic noise generated by children aged } \\ & 6-13 \text { years } \\ \text { - Anthropic noise generated by adults (conversations, } & \text { video calls, physical activity, music) } \\ \text { - Noise from own pets } \\ \text { - Noise of nature (chirping of birds, noise from } \\ \text { - neighborhood animals, wind, water) } \\ \text { unloadingorhood noise (trampling, shouting, loading, and } \\ \text { unoods, music) }\end{array}$

Table 1. Then, 12 questions that were specifically oriented to assess the relationship between noise sensitivity, annoyance, well-being, and work productivity were given and are summarized in Table 2. A last question in Table 2, i.e., Q13, was added to ask for the main perceived source of noise during the remote working activity. 
TABLE 3 | Mean and mode values of the answers given by nonsensitive ( $n==358$ ) to noise respondents on noise annoyance (Q1), work productivity (Q3, Q4, Q5), and mental health and well-being (Q6) for different typologies of remote working environments, considering. Two-tailed $p$-values of significance for the differences between across environments are reported according to the Kruskal Wallis $(\mathrm{KW})$ Test. Specific significant differences $(p$-value $<0.10)$ between environments are given as mean values in italics as a result of the application of the Mann Whitney $U$ Test.

\begin{tabular}{|c|c|c|c|c|c|c|c|c|c|c|}
\hline \multirow[t]{3}{*}{ ID } & Separate & & & & & & & env & ents & \multirow[t]{3}{*}{ KW p-value } \\
\hline & $(n==198)$ & \multicolumn{2}{|c|}{$(n==151)$} & \multicolumn{2}{|c|}{$(n==3)$} & \multicolumn{2}{|c|}{$(n==6)$} & \multicolumn{2}{|c|}{$(n==0)$} & \\
\hline & Mean & Mean & Mode & Mean & Mode & Mean & Mode & Mean & Mode & \\
\hline
\end{tabular}

\begin{tabular}{|c|c|c|c|c|c|c|c|c|c|c|c|}
\hline \multicolumn{12}{|c|}{ Noise annoyance } \\
\hline Q1 & 1.69 & 2.00 & 1.83 & 2.00 & 1.67 & 2.00 & 2.50 & 1.00 & - & - & 0.09 \\
\hline \multicolumn{12}{|c|}{ Work productivity } \\
\hline Q3 & 1.76 & 1.00 & 2.00 & 2.00 & 1.67 & 2.00 & 2.50 & 1.00 & - & - & 0.06 \\
\hline Q4 & 1.71 & 1.00 & 1.83 & 2.00 & 1.67 & 2.00 & 2.33 & 1.00 & - & - & 0.31 \\
\hline Q5 & 1.66 & 1.00 & 1.82 & 1.00 & 1.00 & 1.00 & 2.00 & 1.00 & - & - & 0.13 \\
\hline \multicolumn{12}{|c|}{ Mental health and well-being (interpersonal relationships) } \\
\hline Q6 & 1.72 & 1.00 & 1.77 & 1.00 & 1.67 & 1.00 & 2.00 & 1.00 & - & - & 0.68 \\
\hline
\end{tabular}

Each question, the Likert ranking based on the 5-point scale, and the list of items in the single-choice option were all appropriately defined based on previous studies. Particularly, the article by Di Blasio et al. (2019) and its references were used as main baseline to design the presented questionnaire. Furthermore, specific questions on noise sensitivity were added based on Senese et al. (2012) who validated the Italian version of the "Weinstein Noise Sensitivity Scale (WNSS)."

Answers related to mental health and well-being (Q2) were grouped as suggested in Di Blasio et al. (2019). In particular, clusters turned into: loss of concentration, mental illness (stress), emotional and social feelings (negative feeling such as feeling displeased, negative feelings toward other housemates, anger, loss of motivation), physical symptoms (headache, tiredness, and overstrain), none, others.

Answers related to personal strategies due to occupants' behavior (Q7) were grouped, again as suggested in Di Blasio et al. (2019). In particular, clusters turned into: use of technological tools (headphones with music, noise cancelling headphones), use of adaptive behaviors (take a break, change work task, open the window, close the window, change room, close the room door, plan the return to office), asking people to reduce their voice, none, other, mix of the above. As in the category "other" several answers frequently recurred, the following clusters were added, that is, working in different time, using earplugs, listening to music.

\section{Statistical Analyses}

Statistical analyses were performed using SPSS (IBM Statistics20, IBM, Armonk, NY, United States ). Nonparametric tests were applied to the database that contained data measured with ordinal and nominal scales, according to Sigel and Castellan (1988). Answers given to the questions related to the perceived noise annoyance, work productivity, mental health, and well-being, were separated per each type of environment were respondents performed their remote working activity were considered (i.e., separate room, shared room, outdoor space, other, mix of environments). Then, comparisons were performed first with the Kruskal Wallis (KW) test, which fits the comparison of results for more than two groups of observation, and then with the Mann-Whitney U Test (MWU), which is used to compare two groups of independent observations. The KW test was also applied to the dataset to investigate how noise annoyance is related to different age ranges, professional sectors, and number of people in an office. The relationship between noise annoyance and gender was instead investigated using the MWU test.

According to question Q8 (see Table 2) related to the respondents' perceived noise sensitivity, answers were both considered overall and also grouped into two clusters. In such a second case, if an answer was given with rating 1 or 2 , respondents were considered "non-sensitive to noise," vice versa if an answer was given with ratings 3-5, respondents were considered "sensitive to noise." The dichotomization of the sample was applied to understand the extent to which the perception of being sensitive to noise could affect the answers related to the influence of noise on annoyance, productivity, mental health, and well-being (see Tables 3, 5). Although an overall noise sensitivity index could be obtained as an average among items (Senesi et al., 2012; Aletta et al., 2018), this work only focused on considering the way in which a participant selfperceived of being sensitive to noise. The other items from Q9 to $\mathrm{Q} 12$, in fact, were related to features of reaction to noise and were not accounted for an average. In general, this approach in the data analysis is based on past studies that have highlighted the need of including the sensitivity to noise as a factor (Stansfeld et al., 2021). Furthermore, it allowed exploring the answers given to the perceived noise annoyance (Q1) considering the sample's general characteristics of gender, age range, professional sector, and city of remote working (see Tables 7,8 ), and the number of people that the respondents shared the working or living environment with (see Tables 10 and 11). Based on the aforementioned dichotomization criterion, among the 1934 respondents 1,576 and 358 reported to be sensitive and nonsensitive to noise, respectively. 


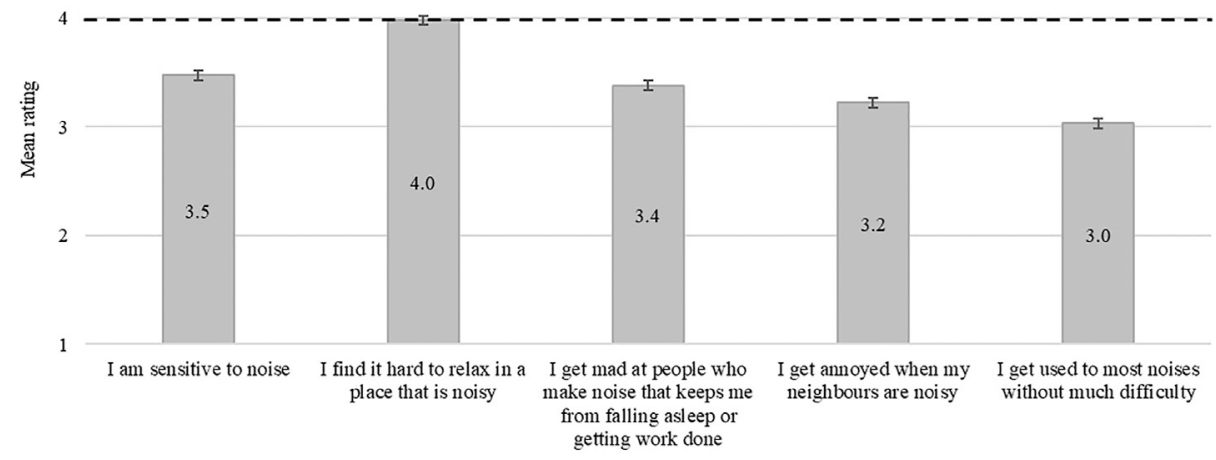

FIGURE 1 | Mean values of the sample's noise sensitivity with respect to specific questions. Error bars represent the 95\% confidence interval (scores from 1, strong disagreement, to 5, strong agreement). The dashed black line corresponds to the mode value obtained for each question (i.e., rating 4).

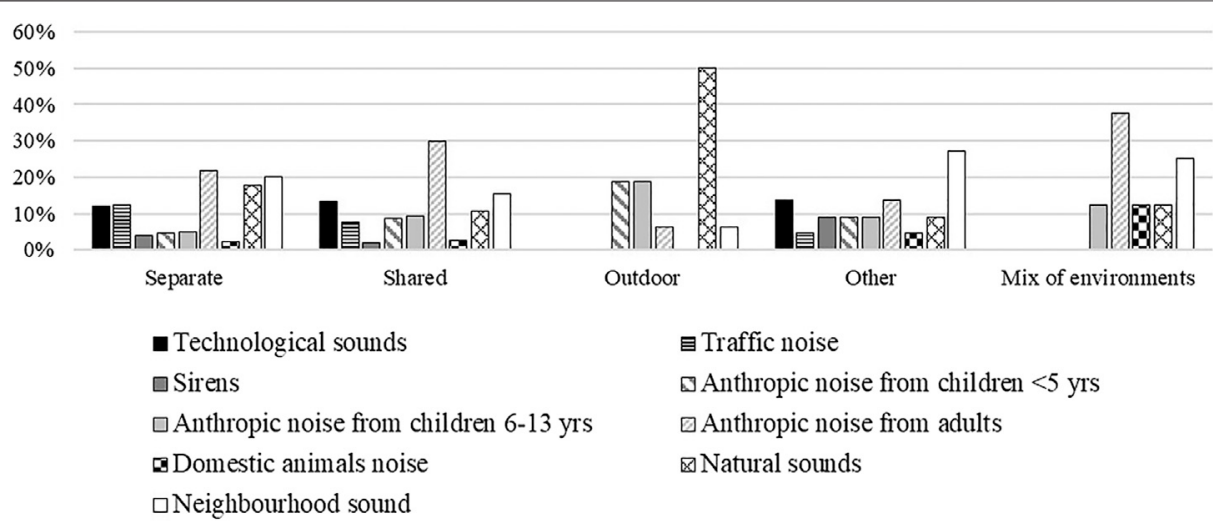

FIGURE 2 | Percentages of main sound source perceived during the remote working hours across all 1,934 respondents, divided per environment where the remote working activity takes place.

\section{RESULTS}

Figure 1 shows the mean values, with errors whiskers in terms of 95\% confidence interval, that workers gave to questions Q8-Q12 related to occupants' sensitivity, i.e., the general reaction of occupants to noise. As rating 1 was labeled as "strongly disagree" and rating 5 as "strongly agree," for questions Q8-Q11 the higher the mean values, the higher can be considered the annoyance due to noise. As the mode values for all these questions consisted in rating 4 , it means that respondents result to be significantly annoyed by noise (Q8) and to find hard relaxing in a noisy environment (Q9). At the same time, as far as Q12 is concerned, the mode value consisting in rating four means that respondents get used to most noises without difficulties although they perceive of being annoyed by them.

As far as the types of noise that respondents were immersed in, the questionnaire aimed at understanding which was the main noise source during the remote working hours. Figure 2 reports the percentages of the answers acquired, which are homogeneously distributed across options based on the remote working environment in which the activity takes place and slightly well represents a correspondence between environment and noise (i.e., the "natural sounds" are reported to be the main source of noise by those who work from outdoor spaces). As separate or shared rooms are the principal environments for remote working, it is interesting that the "anthropic noise generated by adults" is there reported to be the main noise source $(22$ and $30 \%$ in separate and shared rooms, respectively). This outcome, in fact, allows considering such a source as the main one to be controlled.

\section{Effects of Noise on the Perceived Annoyance, Productivity, Mental Health, and Well-Being}

Table 4 shows the results of the extent to which respondents were subjected to noise annoyance (Q1) and the way they perceived an 
TABLE 4 | Mean and mode values of the answers given by sensitive ( $n=1,576)$ to noise respondents on noise annoyance (Q1), work productivity (Q3, Q4, Q5), and mental health and well-being (Q6) for different typologies of remote working environments, considering. Two-tailed $p$-values of significance for the differences between across environments are reported according to the Kruskal Wallis (KW) Test. Specific significant differences $(p$-value $<0.05)$ between environments are given as mean values in italics as a result of the application of the Mann Whitney $\cup$ Test.

\begin{tabular}{|c|c|c|c|c|c|c|c|c|c|c|c|}
\hline \multirow[t]{3}{*}{ ID } & \multicolumn{2}{|c|}{ Separate } & \multicolumn{2}{|c|}{ Shared } & \multicolumn{2}{|c|}{ Outdoor } & \multicolumn{2}{|c|}{ Other } & \multirow{2}{*}{\multicolumn{2}{|c|}{$\begin{array}{c}\begin{array}{c}\text { Mix of } \\
\text { environments }\end{array} \\
(n=8)\end{array}$}} & \multirow[t]{3}{*}{ KW p-value } \\
\hline & \multicolumn{2}{|c|}{$(n=857)$} & \multicolumn{2}{|c|}{$(n=682)$} & \multicolumn{2}{|c|}{$(n=13)$} & \multicolumn{2}{|c|}{$(n=16)$} & & & \\
\hline & Mean & Mode & Mean & Mode & Mean & Mode & Mean & Mode & Mean & Mode & \\
\hline \multicolumn{12}{|c|}{ Noise annoyance } \\
\hline Q1 & 2.19 & 2.00 & 2.46 & 2.00 & 2.23 & 2.00 & 2.25 & 1.00 & 2.25 & 2.00 & 0.00 \\
\hline \multicolumn{12}{|c|}{ Work productivity } \\
\hline Q3 & 2.33 & 2.00 & 2.75 & 3.00 & 2.31 & 2.00 & 2.44 & 1.00 & 2.63 & 2.00 & 0.00 \\
\hline Q4 & 2.33 & 2.00 & 2.69 & 2.00 & 2.77 & 2.00 & 2.25 & 1.00 & 2.38 & 3.00 & 0.00 \\
\hline Q5 & 2.28 & 2.00 & 2.57 & 2.00 & 2.31 & 2.00 & 2.06 & 1.00 & 2.00 & 1.00 & 0.00 \\
\hline \multicolumn{12}{|c|}{ Mental health and well-being (interpersonal relationships) } \\
\hline Q6 & 2.18 & 1.00 & 2.49 & 2.00 & 2.23 & 1.00 & 2.25 & 2.00 & 2.25 & 1.00 & 0.00 \\
\hline
\end{tabular}

TABLE 5 | Mean and mode values of the answers on noise annoyance (Q1), work productivity (Q3, Q4, Q5), and mental health and well-being (Q6) for different typologies of remote working environments. Two-tailed $p$-values of significance for the differences between across environments are reported according to the Kruskal Wallis (KW) Test. Specific significant differences $(p$-value < 0.05) between environments are given as mean values in italics as a result of the application of the Mann Whitney $U$ Test.

\begin{tabular}{|c|c|c|c|c|c|c|c|c|c|c|c|}
\hline \multirow[t]{3}{*}{ ID } & \multirow{2}{*}{\multicolumn{2}{|c|}{$\begin{array}{l}\text { Separate } \\
(n=1,055)\end{array}$}} & \multirow{2}{*}{\multicolumn{2}{|c|}{$\begin{array}{l}\text { Shared } \\
(n=833)\end{array}$}} & \multirow{2}{*}{\multicolumn{2}{|c|}{$\begin{array}{l}\text { Outdoor } \\
(n=16)\end{array}$}} & \multirow{2}{*}{\multicolumn{2}{|c|}{$\begin{array}{l}\text { Other } \\
(n=22) \\
\end{array}$}} & \multirow{2}{*}{\multicolumn{2}{|c|}{$\begin{array}{c}\text { Mix of } \\
\text { environments }\end{array}$}} & \multirow[t]{3}{*}{ KW p-value } \\
\hline & & & & & & & & & & & \\
\hline & Mean & Mode & Mean & Mode & Mean & Mode & Mean & Mode & Mean & Mode & \\
\hline \multicolumn{12}{|c|}{ Noise annoyance } \\
\hline Q1 & 2.09 & 2.00 & 2.34 & 2.00 & 2.13 & 2.00 & 2.32 & 1.00 & 2.25 & 2.00 & 0.00 \\
\hline \multicolumn{12}{|c|}{ Work productivity } \\
\hline Q3 & 2.22 & 2.00 & 2.61 & 2.00 & 2.19 & 2.00 & 2.45 & 1.00 & 2.63 & 2.00 & 0.00 \\
\hline Q4 & 2.22 & 1.00 & 2.53 & 2.00 & 2.56 & 2.00 & 2.27 & 1.00 & 2.38 & 3.00 & 0.00 \\
\hline Q5 & 2.16 & 1.00 & 2.43 & 2.00 & 2.06 & 2.00 & 2.05 & 1.00 & 2.00 & 1.00 & 0.00 \\
\hline \multicolumn{12}{|c|}{ Mental health and well-being (interpersonal relationships) } \\
\hline Q6 & 2.10 & 1.00 & 2.36 & 2.00 & 2.13 & 1.00 & 2.18 & 2.00 & 2.25 & 1.00 & 0.00 \\
\hline
\end{tabular}

effect of noise on work productivity (Q3, Q4, and Q5), mental health, and well-being (Q6). Results are given as mean and mode values divided per each environment in which respondents perform their remote working activity. To understand if answers were significantly different among environments, the KW test was first applied overall and, whenever it resulted statistically significant ( $p$-value $<0.05$ ), followed by the MWU test across couples to have specific insights.

All the investigated aspects (Q1, Q3, Q4, Q5, and Q6) resulted to have statistically significant differences whenever respondents performed their remote working activity in a separate or in a shared room of the living environment. Mean values were higher in the case of shared room in the living environment, resulting in a higher degree of perceived noise annoyance, of reduction of work productivity, and of reduction of harmony in the interpersonal relationships at home.

As far as the clustering of the sample is concerned, the answers were also divided per subjective sensitivity to noise (Q8) and the results are reported in Tables 3, 5 for nonsensitive and sensitive respondents, respectively. Although the trend is having higher mean values, thus a higher degree of perceived noise annoyance and reduction of productivity and well-being when the remote working activity is performed in a shared environment rather than in a separate one, only sensitive subjects revealed that such a difference is statistically significant ( $p$-value $<0.05)$. Answers from nonsensitive respondents were statistically significant with a $p$-value $<0.10$ only in the case of perceived noise annoyance and feeling of need to interrupt the working activity under noisy conditions.

\section{Noise Annoyance, Subjective and Environmental Characteristics}

As the main aspect under investigation was related to the perceived noise annoyance during the remote working activity in the COVID-19 pandemic, this section reports the answers to 
TABLE 6 | Mean and standard deviation (St.dev.) values of the answers on noise annoyance (Q1) related to gender, age range, professional sector, and remote working city for different types of environment of the overall sample $(n=1934)$. Two-tailed $p$-values of significance of the differences according to the Mann Whitney U (MWU) or Kruskal Wallis (KW) Test are reported. Statistically significant differences with $p$-values $<0.05$ are reported in bold.

\begin{tabular}{|c|c|c|c|c|c|c|c|c|c|c|c|}
\hline \multirow{2}{*}{-} & & \multicolumn{2}{|c|}{ Separate } & \multicolumn{2}{|c|}{ Shared } & \multicolumn{2}{|c|}{ Outdoor } & \multicolumn{2}{|c|}{ Other } & \multicolumn{2}{|c|}{ Mix of environments } \\
\hline & & Mean & St.dev. & Mean & St.dev. & Mean & St.dev. & Mean & St.dev. & Mean & St.dev. \\
\hline \multicolumn{12}{|c|}{ Gender } \\
\hline & Female & 2.05 & 0.92 & 2.35 & 0.94 & 1.90 & 1.20 & 2.44 & 1.42 & 2.00 & 1.00 \\
\hline & $\mathrm{n}$ & \multicolumn{2}{|c|}{665} & \multicolumn{2}{|c|}{440} & \multicolumn{2}{|c|}{10} & \multicolumn{2}{|c|}{9} & \multicolumn{2}{|c|}{3} \\
\hline & Male & 2.16 & 0.93 & 2.34 & 0.93 & 2.50 & 1.05 & 2.23 & 1.48 & 2.40 & 0.55 \\
\hline & $\mathrm{n}$ & \multirow{2}{*}{\multicolumn{2}{|c|}{390}} & \multicolumn{2}{|c|}{393} & \multirow{2}{*}{\multicolumn{2}{|c|}{6}} & \multicolumn{2}{|c|}{13} & \multirow{2}{*}{\multicolumn{2}{|c|}{$\begin{array}{c}5 \\
057\end{array}$}} \\
\hline & MWU $p$-value & & & & & & & & & & \\
\hline
\end{tabular}

Age range

$\begin{array}{rlll}18-25 & 2.42 & & 0.78 \\ n & & 52 & \\ 26-35 & 2.33 & & 0.97 \\ n & & 296 & \\ 36-50 & 2.18 & & 0.98 \\ n & & 268 & \\ 51-65 & 1.83 & & 0.80 \\ n & & 412 & \\ 65+ & 1.93 & & 1.14 \\ n & & 27 & \\ \text { KW } \boldsymbol{p} \text {-value } & & \mathbf{0 . 0 0} & \end{array}$

$\begin{array}{ccc}2.05 & & 0.69 \\ 2.38 & 20 & 0.87 \\ 2.57 & 204 & 0.99 \\ 2.20 & 249 & 0.92 \\ 1.86 & 353 & 0.69 \\ & 7 & \\ & \mathbf{0 . 0 0} & \end{array}$

$\begin{array}{ccc}2.00 & & 1.41 \\ 2.00 & 2 & 1.41 \\ 2.67 & 4 & 1.21 \\ 1.50 & 6 & 0.58 \\ - & 4 & - \\ & - & - \\ & 0.36 & \end{array}$

$\begin{array}{ccc}- & - & - \\ 1.67 & - & 0.58 \\ 2.67 & 3 & 1.37 \\ 2.31 & 6 & 1.60 \\ - & 13 & - \\ & - & \\ & 0.55 & \end{array}$

$\begin{array}{ccc}- & & - \\ 2.50 & - & 0.71 \\ 2.20 & 2 & 0.84 \\ 2.00 & 5 & 0.00 \\ - & 1 & - \\ & - & \\ & 0.81 & \end{array}$

Professional sector

Technical
$n$
Engineering
$n$
Management
$n$
Administration
$n$

$\begin{array}{lll}1.84 & & 0.82 \\ 2.39 & 201 & 0.95 \\ 1.80 & 307 & 0.84 \\ 1.83 & 85 & 0.78 \\ 2.47 & 192 & 1.01 \\ 2.00 & 74 & 0.93 \\ 2.27 & 57 & 0.98 \\ 2.51 & 22 & 0.95 \\ 1.79 & 51 & 0.92 \\ 2.14 & 28 & 1.04 \\ 1.88 & 22 & 0.72 \\ & 16 & \\ & \mathbf{0 . 0 0} & \end{array}$

$\begin{array}{ll}2.25 & 0.96\end{array}$

$\begin{array}{ll}1.80 & 0.45\end{array}$

$2.33 \quad 1.75$

$2.50 \quad 0.71$

Creative, design and architecture

$n$
Other
$n$
Teaching

Researcher

Sales and public affairs

Teaching and researcher

$$
\begin{array}{r}
n \\
\text { Services } \\
n
\end{array}
$$

KW $p$-value

$\begin{array}{lll}2.48 & 167 & 0.92 \\ & 176 & \end{array}$

$\begin{array}{lll}1.80 & & 0.45 \\ 2.50 & 5 & 1.73 \\ & 4 & \end{array}$

$\begin{array}{lll}2.67 & 6 & \\ & 3 & 2.08\end{array}$




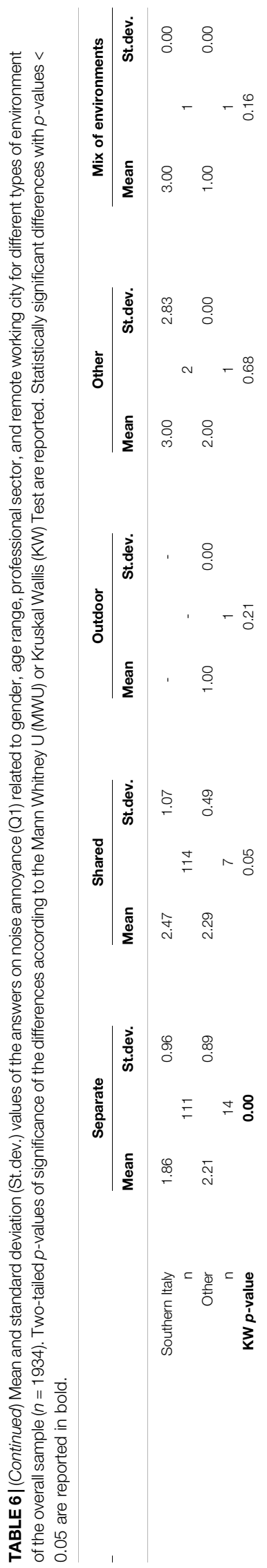

the specific question on noise annoyance (Q1) in relationship to different characteristics of the sample.

\section{Noise Annoyance and Subjective Characteristics}

Mean values and standard deviations of the noise annoyance scores were first analyzed according to the subjective characteristics of gender, age range, professional sector, and city of remote working activity. Table 6 reports the results for the overall sample $(n=1934)$, always divided based on the environment where the remote working activity was mainly performed. Applying the proper statistical tests of KW and/or MWU, the main outcomes can be summarized as follows:

- The factor gender does not bring to statistically significant different results on the perceived noise annoyance;

- The factor age range brings to statistically significant differences on the perceived noise annoyance whether the remote working activity was performed in a separate or in a shared room of the living environment. In particular, respondents who worked in a separate room of the living environment revealed to be annoyed by noise to a greater extent if they were younger. Statistically significant differences were found for the age group 18-25 with respect to $36-50,51-65$, and $65+$; then for the age group 26-35 with respect to $36-50,51-65$, and 65+; then for the age group 36-50 with respect to 51-65. A different trend was found for respondents who performed their remote working activity in a shared room of the environment, with the maximum perception of noise annoyance for the 36-50 age group. In such a case, statistically significant differences were found for the age group 18-25 with respect to 36-50; then for the age group 26-35 with respect to $36-50$ and 51-65; then for the age group 36-50 with respect to 51-65 and $65+$;

- The factor professional sector brings again to statistically significant differences on the perceived noise annoyance whether the remote working activity was performed in a separate or in a shared room of the living environment. In the first case, i.e., separate room, researchers exhibited the highest mean value of noise annoyance. As far as the differences are concerned, people working in the technical sector gave different answers with respect to people working in management, administration, creative/design/architecture sectors; people working in the engineering sector gave different answers with respect to people working in management, administration, creative/design/architecture; people working in the management sector gave different answers with respect to people administration. In the second case, i.e., shared room, workers in the creative, design, and architecture field reported to be the most annoyed by noise. Then, specifically, people working in the technical sector gave different answers with respect to people working in management; people working in the engineering sector gave different answers with respect to people working in management and administration; 
TABLE 7 | Mean and standard deviation (St.dev.) values of the answers given by nonsensitive to noise respondents $(n=358)$ on noise annoyance (Q1) related to gender, age range, professional sector, and remote working city for different types of environment. Two-tailed $p$-values of significance of the differences according to the Mann Whitney U (MWU) or Kruskal Wallis (KW) Test are reported. Statistically significant differences with $p$-values $<0.05$ are reported in bold.

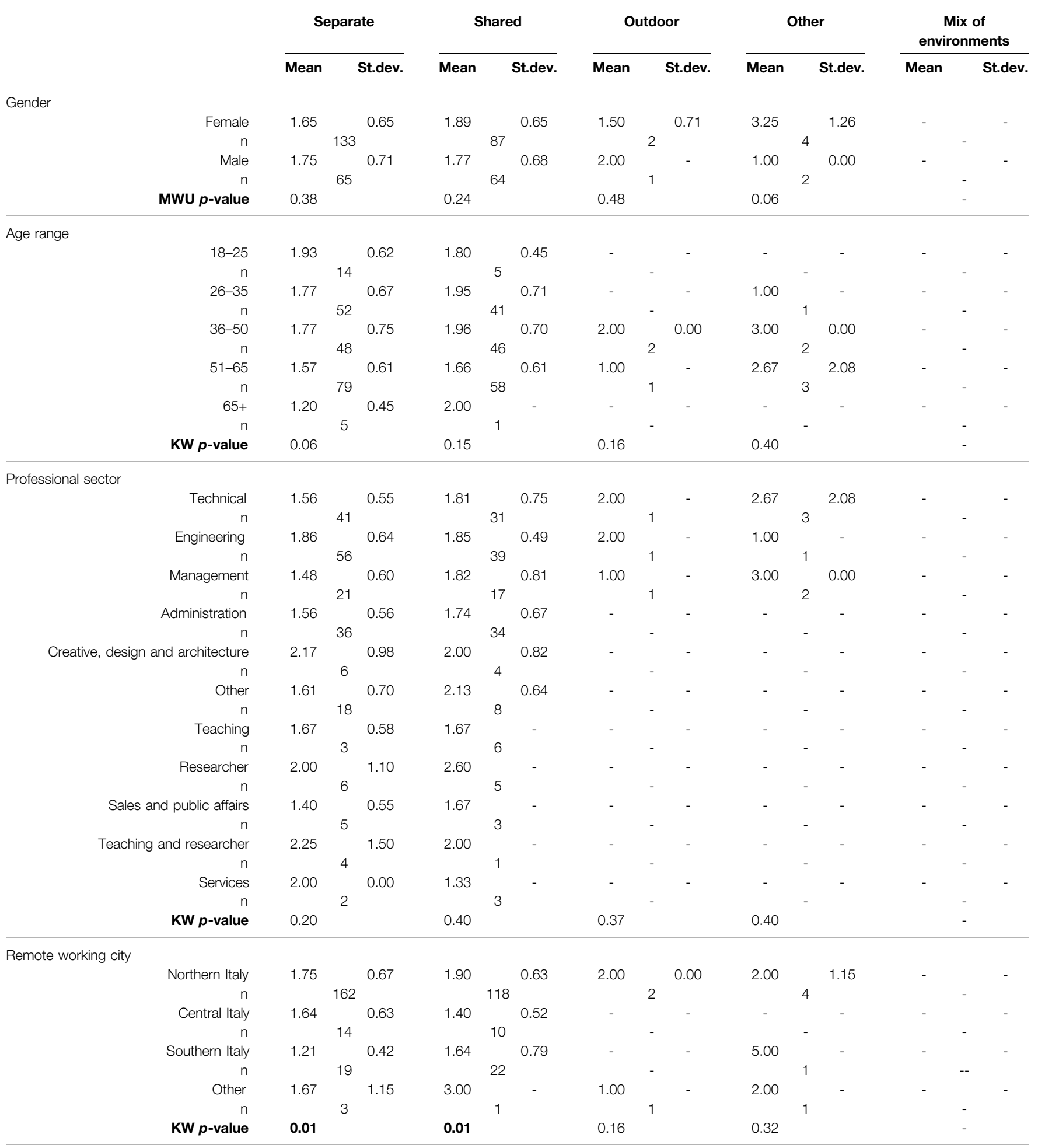

people working in the management sector gave different answers with respect to people administration and creative/design/architecture;
- The factor remote working city brings to statistically significant differences on the perceived noise annoyance whether the remote working activity was performed in a 
TABLE 8 | Mean and standard deviation (St.dev.) values of the answers given by sensitive to noise respondents $(n=1,576)$ on noise annoyance (Q1) related to gender, age range, professional sector, and remote working city for different types of environment. Two-tailed $p$-values of significance of the differences according to the Mann Whitney U (MWU) or Kruskal Wallis (KW) Test are reported. Statistically significant differences with $p$-values $<0.05$ are reported in bold.

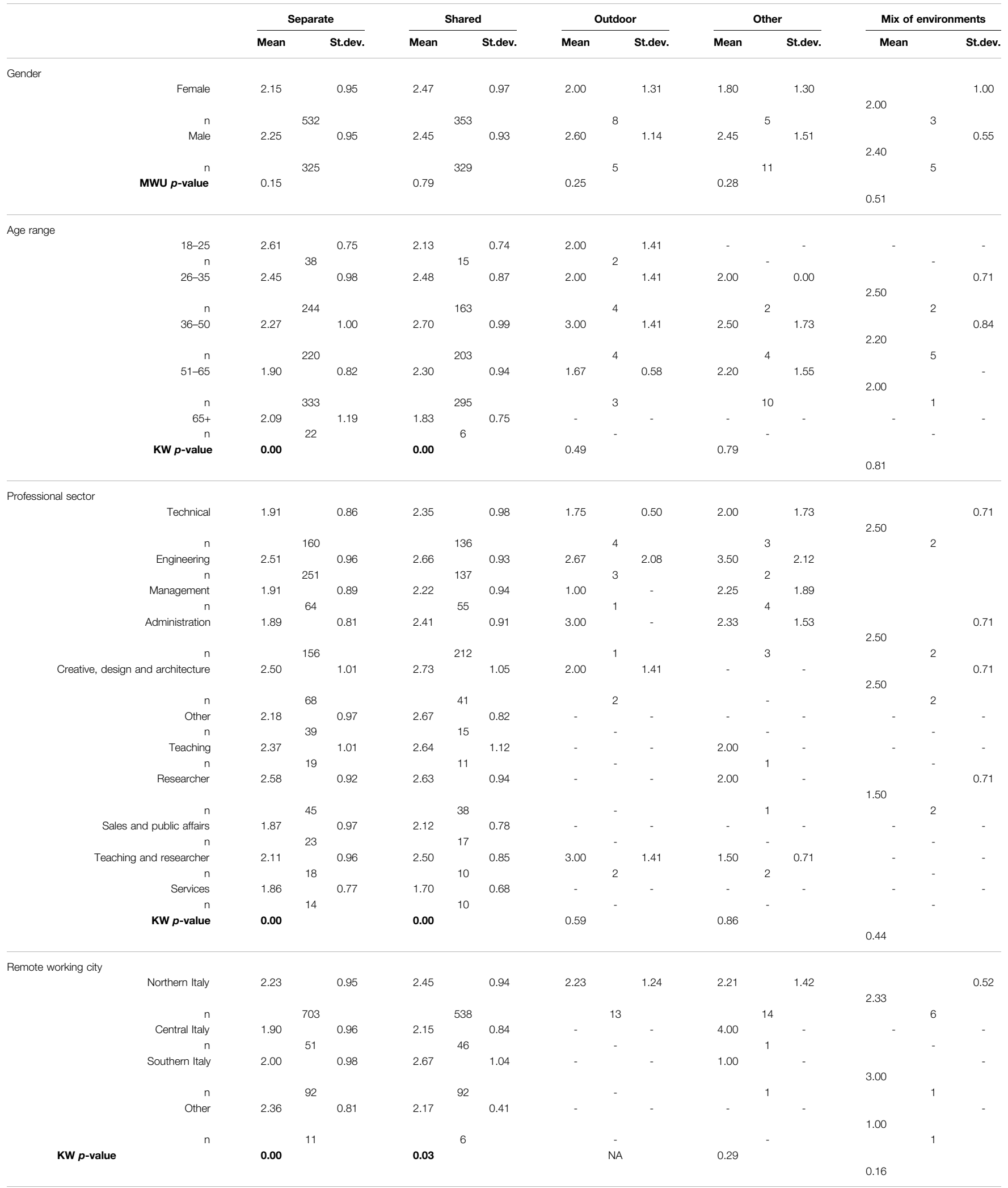


TABLE 9 | Mean and standard deviation (St.dev.) values of the answers on noise annoyance (Q1) related to the number of people in the remote working environment and in the overall living environment, considering the overall sample $(n=1934)$. Two-tailed $p$-values of significance of the differences according to the Kruskal Wallis (KW) Test are reported. Statistically significant differences with $p$-values $<0.05$ are reported in bold.

\begin{tabular}{|c|c|c|c|c|c|c|c|c|c|c|c|}
\hline & & \multicolumn{2}{|c|}{ Separate } & \multicolumn{2}{|c|}{ Shared } & \multicolumn{2}{|c|}{ Outdoor } & \multicolumn{2}{|c|}{ Other } & \multicolumn{2}{|c|}{$\begin{array}{l}\text { Mix of } \\
\text { environments }\end{array}$} \\
\hline & & Mean & St.dev. & Mean & St.dev. & Mean & St.dev. & Mean & St.dev. & Mean & St.dev. \\
\hline \multirow{9}{*}{$\begin{array}{l}\text { Number of people in the remote working } \\
\text { environment (yourself excluded) }\end{array}$} & 0 & 2.04 & 0.92 & 1.94 & 0.83 & 1.86 & 1.07 & 1.83 & 1.11 & 1.67 & 0.58 \\
\hline & $\mathrm{n}$ & \multicolumn{2}{|c|}{843} & \multicolumn{2}{|c|}{235} & \multicolumn{2}{|c|}{7} & \multicolumn{2}{|c|}{12} & \multicolumn{2}{|c|}{3} \\
\hline & $1-2$ & 2.29 & 0.92 & 2.44 & 0.89 & 2.29 & 1.38 & 2.33 & 1.75 & 2.60 & 0.55 \\
\hline & $\mathrm{n}$ & \multicolumn{2}{|c|}{190} & \multicolumn{2}{|c|}{535} & \multicolumn{2}{|c|}{7} & \multicolumn{2}{|c|}{6} & \multicolumn{2}{|c|}{5} \\
\hline & $3-4$ & 2.63 & 0.96 & 3.08 & 1.10 & 2.50 & 0.71 & 3.33 & 0.58 & - & - \\
\hline & $\mathrm{n}$ & \multicolumn{2}{|c|}{19} & \multicolumn{2}{|c|}{61} & \multicolumn{2}{|c|}{2} & \multicolumn{2}{|c|}{3} & \multicolumn{2}{|c|}{ - } \\
\hline & $5+$ & 1.67 & 0.58 & 2.00 & 0.00 & - & - & 5.00 & 0.00 & - & - \\
\hline & $\mathrm{n}$ & \multicolumn{2}{|c|}{3} & \multicolumn{2}{|c|}{2} & \multicolumn{2}{|r|}{ - } & \multicolumn{2}{|c|}{1} & \multirow{2}{*}{\multicolumn{2}{|c|}{$0.07^{-}$}} \\
\hline & KW p-value & 0.00 & & 0.00 & & 0.51 & & 0.11 & & & \\
\hline \multirow{9}{*}{$\begin{array}{l}\text { Number of people in the overall living environment } \\
\text { (yourself excluded) }\end{array}$} & 0 & 1.97 & 0.95 & 1.96 & 0.87 & 1.00 & 0.00 & 1.50 & 0.53 & 2.00 & 0.00 \\
\hline & $\mathrm{n}$ & \multicolumn{2}{|c|}{176} & \multicolumn{2}{|c|}{94} & \multicolumn{2}{|c|}{2} & \multicolumn{2}{|c|}{10} & \multicolumn{2}{|c|}{2} \\
\hline & $1-2$ & 2.07 & 0.89 & 2.31 & 0.91 & 2.17 & 0.98 & 2.33 & 2.31 & 2.00 & 1.00 \\
\hline & $\mathrm{n}$ & \multicolumn{2}{|c|}{563} & & 86 & & 6 & & 3 & & 3 \\
\hline & $3-4$ & 2.19 & 0.95 & 2.54 & 0.96 & 2.38 & 1.30 & 3.38 & 1.41 & 2.67 & 0.58 \\
\hline & $\mathrm{n}$ & & 94 & & 34 & & 8 & & 8 & & 3 \\
\hline & $5+$ & 2.59 & 1.14 & 2.74 & 0.87 & - & - & 2.00 & 0.00 & - & - \\
\hline & $n$ & & 2 & & 9 & & - & & 1 & & - \\
\hline & KW p-value & 0.01 & & 0.00 & & 0.18 & & 0.07 & & 0.42 & \\
\hline
\end{tabular}

separate or in a shared room of the living environment. For people working in a separate room, being in northern Italy brought to a greater higher degree of perceived noise annoyance with respect to central and southern Italy respondents. For people working in shared rooms, statistically significant differences were found for northern vs. central Italy and for central vs. southern Italy.

\section{Sensitive and Nonsensitive to Noise Subjects}

Considering the clustered sample, mean values and standard deviations of the noise annoyance scores were then analyzed for respondents who revealed to be nonsensitive $(n=358$, Table 7$)$ or sensitive ( $n=1,576$, Table 8 ) to noise. In both the cases, the factor gender did not bring to statistically significant differences, when the remote working activity was performed neither in a separate nor in a shared room of the living environment.

Then, in the case of nonsensitive to noise respondents $(n=$ 358 , Table 7), the smaller number of cases considered did not lead to statistically significant differences on perceived noise annoyance for the factors age range and professional sector too. The factor remote working city showed differences for northern and southern Italy, and for northern and central and southern Italy whether the respondent used to work in a separate or shared room of the living environment, respectively.

In the case of sensitive to noise respondents ( $n=1,576$, Table 8), the main outcomes can be summarized as follows:

- The same results in terms of significant differences outlined for the overall sample were found for the factor age range. In particular, statistically significant differences on the perceived noise annoyance were found whether the remote working activity was performed in a separate or a shared room of the living environment;

- The factor professional sector revealed some slight differences. Overall, in the case of people working in a separate room, researchers exhibited the highest mean value of noise annoyance. Then, people working in the technical sector gave different answers with respect to people working in engineering, creative/design/architecture, teaching, and research sectors; people working in the engineering sector gave different answers with respect to people working in management, administration, other, sales and public affairs, services; people working in the management sector gave different answers with respect to people working in creative/ design/architecture, research; people working in the administration sector gave different answers with respect to people working in creative/design/architecture, teaching, research; people working in the creative/design/architecture sector gave different answers with respect to people working in sales and public affairs, services; people working in other sectors gave different answers with respect to people working in research; people working in the research sector gave different answers with respect to people working in sales and public affairs, teaching and research, services. For people working in a shared room, workers in the creative, design, and architecture field reported to be the most annoyed by noise. Then, people working in the technical sector gave different answers with respect to people working in engineering and services; people working in engineering gave different answers with respect to people working in management, administration, sales and public affairs, services; people working in the management sector gave different answers with respect to people working in creative/design/ 
TABLE 10 | Mean and standard deviation (St.dev.) values of the answers given by nonsensitive to noise respondents ( $n=358$ ) on noise annoyance (Q1) related to the number of people in the remote working environment and in the overall living environment. Two-tailed $p$-values of significance of the differences according to the Kruskal Wallis (KW) Test are reported. Statistically significant differences with $p$-values $<0.05$ are reported in bold.

\begin{tabular}{|c|c|c|c|c|c|c|c|c|c|c|c|}
\hline & & \multicolumn{2}{|c|}{ Separate } & \multicolumn{2}{|c|}{ Shared } & \multicolumn{2}{|c|}{ Outdoor } & \multicolumn{2}{|c|}{ Other } & \multicolumn{2}{|c|}{$\begin{array}{l}\text { Mix of } \\
\text { environments }\end{array}$} \\
\hline & & Mean & St.dev. & Mean & St.dev. & Mean & St.dev. & Mean & St.dev. & Mean & St.dev. \\
\hline \multirow{9}{*}{$\begin{array}{l}\text { Number of people in the remote working environment } \\
\text { (yourself excluded) }\end{array}$} & 0 & 1.66 & 0.64 & 1.69 & 0.62 & 1.00 & - & 1.50 & 0.71 & - & - \\
\hline & $\mathrm{n}$ & \multicolumn{2}{|c|}{160} & \multicolumn{2}{|c|}{48} & \multicolumn{2}{|c|}{1} & \multicolumn{2}{|c|}{2} & \multicolumn{2}{|r|}{-} \\
\hline & $1-2$ & 1.71 & 0.67 & 1.86 & 0.62 & 2.00 & - & 1.00 & - & - & - \\
\hline & $\mathrm{n}$ & \multicolumn{2}{|c|}{35} & \multicolumn{2}{|c|}{93} & \multicolumn{2}{|r|}{1} & \multicolumn{2}{|c|}{1} & \multicolumn{2}{|c|}{-} \\
\hline & $3-4$ & 3.00 & 1.00 & 2.30 & 1.06 & 2.00 & - & 3.00 & 0.00 & - & - \\
\hline & $n$ & \multicolumn{2}{|c|}{3} & \multicolumn{2}{|c|}{10} & \multicolumn{2}{|c|}{1} & \multicolumn{2}{|c|}{2} & \multicolumn{2}{|c|}{ - } \\
\hline & $5+$ & - & - & - & - & - & - & 5.00 & - & - & - \\
\hline & $\mathrm{n}$ & \multicolumn{2}{|r|}{ - } & \multicolumn{2}{|c|}{-} & \multicolumn{2}{|c|}{ - } & \multicolumn{2}{|c|}{1} & \multicolumn{2}{|c|}{-} \\
\hline & KW p-value & 0.04 & & 0.10 & & 0.37 & & 0.20 & & & - \\
\hline \multirow{9}{*}{$\begin{array}{l}\text { Number of people in the overall living environment } \\
\text { (yourself excluded) }\end{array}$} & 0 & 1.58 & 0.71 & 1.88 & 0.62 & 1.00 & - & 1.00 & - & - & - \\
\hline & $\mathrm{n}$ & \multicolumn{2}{|c|}{48} & \multicolumn{2}{|c|}{16} & \multicolumn{2}{|r|}{1} & \multicolumn{2}{|c|}{1} & \multicolumn{2}{|c|}{-} \\
\hline & $1-2$ & 1.67 & 0.64 & 1.78 & 0.64 & 2.00 & - & - & - & - & - \\
\hline & $\mathrm{n}$ & \multicolumn{2}{|c|}{100} & & 38 & & 1 & & - & & - \\
\hline & $3-4$ & 1.80 & 0.68 & 1.86 & 0.68 & 2.00 & - & 2.80 & 1.48 & - & - \\
\hline & $n$ & & 46 & & 12 & & 1 & & 5 & & - \\
\hline & $5+$ & 2.00 & 0.82 & 2.40 & 1.14 & - & - & - & - & - & - \\
\hline & $n$ & & 4 & & 5 & & - & & - & & - \\
\hline & KW p-value & 0.24 & & 0.50 & & 0.37 & & 0.23 & & & - \\
\hline
\end{tabular}

TABLE 11 | Mean and standard deviation (St.dev.) values of the answers given by sensitive to noise respondents $(n=1,576)$ on noise annoyance (Q1) related to the number of people in the remote working environment and in the overall living environment. Two-tailed $p$-values of significance of the differences according to the Kruskal Wallis (KW) Test are reported. Statistically significant differences with $p$-values $<0.05$ are reported in bold.

\begin{tabular}{|c|c|c|c|c|c|c|c|c|c|c|c|}
\hline & & \multicolumn{2}{|c|}{ Separate } & \multicolumn{2}{|c|}{ Shared } & \multicolumn{2}{|c|}{ Outdoor } & \multicolumn{2}{|c|}{ Other } & \multicolumn{2}{|c|}{$\begin{array}{l}\text { Mix of } \\
\text { environments }\end{array}$} \\
\hline & & Mean & St.dev. & Mean & St.dev. & Mean & St.dev. & Mean & St.dev. & Mean & St.dev. \\
\hline \multirow{9}{*}{$\begin{array}{l}\text { Number of people in the remote working environment } \\
\text { (yourself excluded) }\end{array}$} & 0 & 2.13 & 0.95 & 2.01 & 0.86 & 2.00 & 1.10 & 1.90 & 1.20 & 1.67 & 0.58 \\
\hline & $n$ & \multicolumn{2}{|c|}{683} & \multicolumn{2}{|c|}{187} & \multicolumn{2}{|r|}{6} & \multicolumn{2}{|c|}{10} & \multicolumn{2}{|c|}{3} \\
\hline & $1-2$ & 2.43 & 0.92 & 2.56 & 0.89 & 2.33 & 1.51 & 2.60 & 1.82 & 2.60 & 0.55 \\
\hline & $\mathrm{n}$ & \multicolumn{2}{|c|}{155} & \multicolumn{2}{|c|}{442} & \multicolumn{2}{|c|}{6} & \multicolumn{2}{|c|}{5} & \multicolumn{2}{|c|}{5} \\
\hline & $3-4$ & 2.56 & 0.96 & 3.24 & 1.05 & 3.00 & - & 4.00 & - & - & - \\
\hline & $\mathrm{n}$ & \multicolumn{2}{|c|}{16} & \multicolumn{2}{|c|}{51} & \multicolumn{2}{|c|}{1} & \multicolumn{2}{|c|}{1} & \multicolumn{2}{|c|}{-} \\
\hline & $5+$ & 1.67 & 0.58 & 2.00 & 0.00 & - & - & - & - & - & - \\
\hline & $\mathrm{n}$ & \multicolumn{2}{|c|}{3} & \multicolumn{2}{|c|}{2} & \multicolumn{2}{|r|}{ 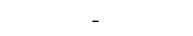 } & \multicolumn{2}{|c|}{ - } & \multicolumn{2}{|c|}{-} \\
\hline & KW p-value & \multicolumn{2}{|c|}{0.00} & \multicolumn{2}{|c|}{111111110.00} & 0.58 & & 0.44 & & 0.07 & \\
\hline \multirow{9}{*}{$\begin{array}{l}\text { Number of people in the overall living environment } \\
\text { (yourself excluded) }\end{array}$} & 0 & 2.11 & 0.99 & 1.97 & 0.91 & 1.00 & - & 1.56 & 0.53 & 2.00 & 0.00 \\
\hline & $\mathrm{n}$ & \multicolumn{2}{|c|}{128} & \multicolumn{2}{|c|}{78} & \multicolumn{2}{|c|}{1} & \multicolumn{2}{|c|}{9} & & 2 \\
\hline & $1-2$ & 2.15 & 0.92 & 2.42 & 0.92 & 2.20 & 1.10 & 2.33 & 2.31 & 2.00 & 1.00 \\
\hline & $\mathrm{n}$ & & 33 & & 98 & & 5 & & 3 & & 3 \\
\hline & $3-4$ & 2.26 & 0.97 & 2.69 & 0.95 & 2.43 & 1.40 & 4.33 & 0.58 & 2.67 & 0.58 \\
\hline & $\mathrm{n}$ & & 48 & & 92 & & 7 & & 3 & & 3 \\
\hline & $5+$ & 2.72 & 1.18 & 2.86 & 0.77 & - & - & 2.00 & - & - & - \\
\hline & $\mathrm{n}$ & & 8 & & 4 & & - & & 1 & & - \\
\hline & KW p-value & 0.07 & & 0.00 & & 0.44 & & 0.10 & & 0.42 & \\
\hline
\end{tabular}

architecture, research; people working in the services sector gave different answers with respect to people working in technical, engineering, administration, creative/design/ architecture, other, research;

- The factor remote working city brings once more to statistically significant differences on the perceived noise annoyance whether the remote working activity was performed in a separate or in a shared room of the living environment.
Indeed, the same results in terms of significant differences outlined for the overall sample were found.

\section{Noise Annoyance and Number of People in the Environment}

As a second goal of the data analysis, mean values and standard deviations of the noise annoyance scores were then analyzed according to the number of people who were present either in the 


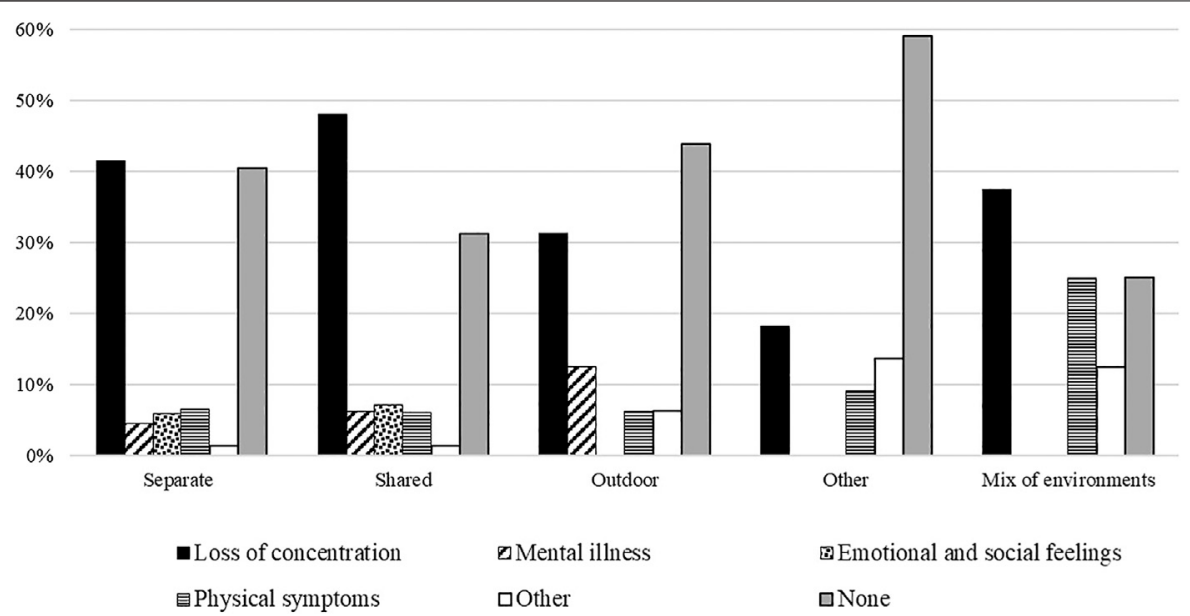

FIGURE 3 | Percentages of the subjective ratings of the effects of noise in the different remote working environments on mental health and well-being (i.e., feelings and symptoms).

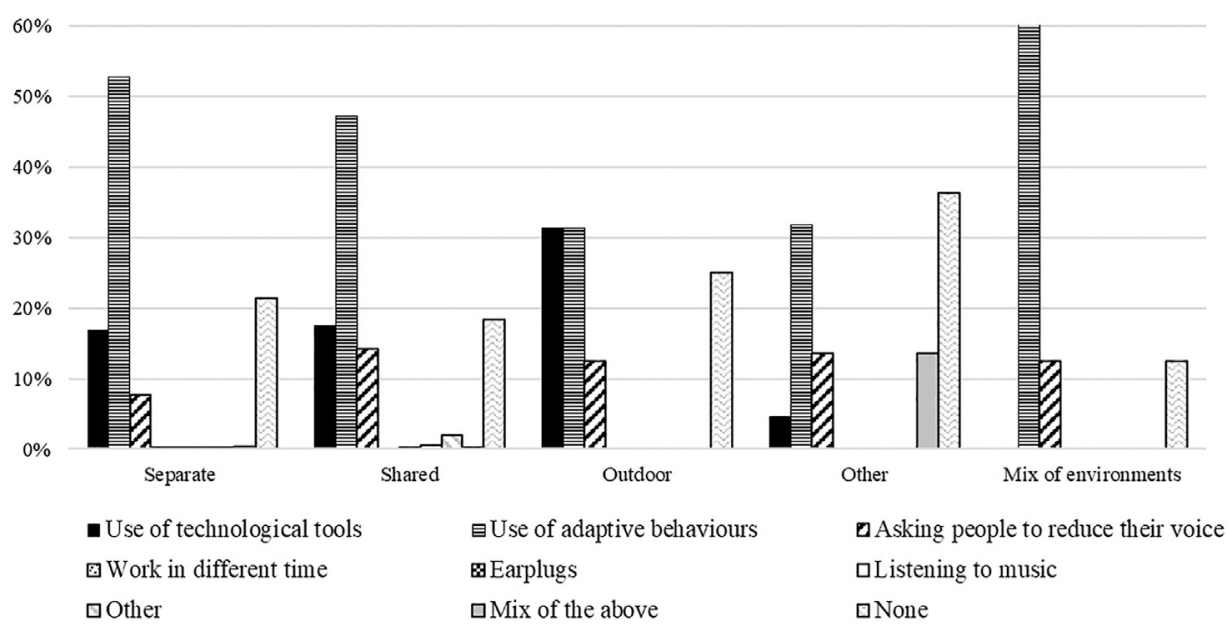

FIGURE 4 | Percentages of the subjective ratings of the effects of noise in the different remote working environments on occupants' behavior (i.e., strategies to cope with noise).

same room of remote working or in the overall living environment. Table 9 reports the results for the overall sample. Overall, the greater was the number of people in the working environment or in the general living environment, the greater was the perceived noise annoyance.

Considering the factor of number of people in the remote working environment, statistically significant differences in the case of separate room for 0 and 1-2,3-4 groups, and in the case of shared room for 0 and 1-2, 3-4 groups, and for 1-2 and 3-4 groups. As far as the number of people in the overall living environment is concerned, statistically significant differences in the case of separate room for 0 and 3-4, $5+$ groups, and for 1-2 and $5+$ groups, and in the case of shared room for 0 and 1-2,3-4, $5+$ groups, and for 1-2 and 3-4, $5+$ groups.

\section{Sensitive and Nonsensitive to Noise Subjects}

Similarly, also for the number of people in the environments the sample was split based on the respondents' sensitivity to noise.

In the case of nonsensitive to noise respondents $(n=358$, Table 10), consider the factor of number of people in the remote working environment, statistically significant differences in the case of separate room for 0 and 3-4 groups, and 1-2 and 3-4 groups. As far as the number of people in the overall living environment is concerned, no statistically significant differences among groups were found.

In the case of sensitive to noise respondents ( $n=1,576$, Table 11), consider the factor of number of people in the remote working environment, statistically significant differences in the case of separate room for 0 and 1-2 groups, 
and 1-2 and 3-4 groups, and in the case of shared room for 0 and 1-2, 3-4 groups. As far as the number of people in the overall living environment is concerned, statistically significant differences in the case of shared room for 0 and $5+$ groups, and for 1-2 and $5+$ groups.

\section{Occupants' Behavior}

Questions Q2 and Q7 were designed to understand the perceived mental health well-being, in terms of symptoms generated by noise annoyance, and the actions that respondents were willing to make to reduce annoyance, respectively.

Figure 3 shows that, overall, remote workers either do not complain about noise and report of not feeling symptoms $(39.9 \%$ of the respondents) or complain about feeling a loss of concentration (35.3\%). Symptoms related to mental illness (i.e., stress) and emotional/social feelings (i.e., negative feeling such as feeling displeased, negative feelings toward other housemates, anger, loss of motivation) are reported by only workers who perform remote working activity in a separate or shared room (less than $10 \%$ of respondents anyway) and, in the first case, in outdoor spaces (12.5\% of respondents).

Figure 4 reports the main strategy used to reduce the annoyance resulting from noise during remote working activity. Less than $23 \%$ of the respondents does not adopt any strategy to this aim, and on average the 14 and $12 \%$ of respondents either use technological tools to mask or cancel noise (e.g., wearing headphones) or ask people to reduce their voice, respectively. The majority of respondents (47.6\%) reported to use adaptive behaviors to actively solve the problem of noise annoyance in the working hours. In particular, the main strategies adopted were related to take a break, change room/ environment, switch between working tasks, or interact with the environment by opening/closing the windows to change the environment's soundscape.

\section{DISCUSSION}

Several studies carried out before and during the pandemic period of COVID-19 revealed a significant decrease in outdoor measured noise levels, as strong measures such as the "stay at home" strategy were taken by the National Governments to limit the spreading of the infection. Aletta et al. (2020a) measured a decrease by about $65 \%$ of the use of vehicles in a study on noise mapping in Rome (IT) during the pandemic period. Bartalucci et al. (2020), on a weekly basis, assessed a reduction up to $10 \mathrm{~dB}$ in terms of $\mathrm{L}_{\mathrm{den}}$ during a long-term monitoring of traffic noise in Monza (IT). An average decrease in $\mathrm{L}_{\mathrm{den}}$ by $5 \mathrm{~dB}$ was reported by Hornberg et al. (2021), who reviewed a number of studies related to noise level decreases during and after the pandemic period. In a study by the Soundscape and noise observatory of Greater Lyon (Acoucité, 2020), 21 monitoring stations spread in five French cities measured outdoor noise before and during the lockdown period due to the pandemic, revealing a reduction in $\mathrm{L}_{\mathrm{den}}$ by up $6 \mathrm{~dB}$ in the weekdays and up to $9 \mathrm{~dB}$ in the weekends. At the same time, this latter study also investigated on the dwellers' perception of the sound environment during the lockdown: they gave more positive attributes to their impression, such as "calm," "pleasant," "peaceful," and thus revealed a link between the soundscape perception and composition. As before the pandemic period traffic noise was typically predominant in the cities, during the lockdown the hierarchy of sound sources has been reversed allowing for more anthropic sounds to be heard (Aletta et al., 2020b; Sakagami, 2020). Furthermore, Manzano et al. (2021) report a significant shift from human-generated (e.g., traffic) and anthropic sourcers to animal and natural sources. Şentop Dümen and Şaher (2020) stressed the negative effect of anthropic sounds as they observed, from the outcomes of an online survey administered in Turkey to 1,053 subjects, that annoyance from noise generated by neighbors did not change significantly before and during the pandemic period, whereas annoyance from noise generated by dwellers significicantly increased. These studies corroborate at several levels the findings of the present study, as the categories of sources related to "anthropic noise," "natural sounds," and "neighborhood sounds" were the most perceived at home during the remote working hours. On the contrary, "traffic noise" and "sirens" were reported to be the predominantly perceived noise source by less than $15 \%$ of respondents on average.

As the soundscape of remote working environments, which correspond to living environments from the spreading of COVID-19 pandemic, has profoundly changed in the last year, it is necessary to account for the new main sound sources perceived to provide an effective home design. In light of this, noise control should not be the only approach, but should be integrated with a perceptual and multisensory perspective as suggested by Torresin et al. (2020b), also considering participatory design practices that account for the dweller/worker premises to enable the complex building-user interrelations.

\section{Perceived Noise Annoyance, Productivity, Mental Health, and Well-Being}

To the authors' knowledge, only few studies investigated the problem of noise annoyance under a remote working setting. However, it is possible to make a comparison with the outcomes from studies related to noise annoyance in offices as in both settings the predominantly perceived noise source was found to be of anthropic nature.

Overall, remote workers were most annoyed by noise (Q1) when they performed their working activity in a shared space of the house than in a separate environment. This outcome was confirmed also splitting the sample based on their sensitivity to noise (Q8), and corroborated studies in which noise annoyance was assessed as higher in shared and larger offices than in smaller ones (Danielsson, 2005; Di Blasio et al., 2019).

As far as the perception of productivity is concerned, workers who performed activity in shared environments of the house reported a higher sense of loss. In summary, they perceived more that noise interrupts them during the remote working activity, does not allow them to work as much as they would, and reduces their working performance. Again, this outcome confirms past works by Di Blasio et al. (2019) and is similar to what KaarlelaTuomaala et al. (2009) found in relation to the perceived feeling of wasting time and loose productivity when changing workspace from a private to an open-plan office.

In relation to mental health and well-being perception, the questionnaire distinguished queries on the base of issues related 
to feelings and symptoms (Q2) and interpersonal relationships (Q6). As far as symptoms are concerned, despite that about an average $40 \%$ of respondents reported to have no experience of feelings/symptoms related to noise during the remote working hours, the main consequence of noise indicated by approximately $35 \%$ of respondents, on average, was a loss of concentration. This outcome is in agreement with other studies that highlighted a significant increase in deconcentration during the working hours (Banbury and Berry, 2005; Kaarlela-Tuomaala et al., 2009; Di Blasio et al., 2019) and getting even worse as the office size increased itself (Pejtersen et al., 2006). As far as the interpersonal relationships are concerned, workers from shared environments in the house reported a sense of compromising the harmony at home to a statistically significant greater extent than workers from separate environments. These findings are in agreement with Brennan et al. (2002) and Di Blasio et al. (2019), who reported difficulties and less satisfaction in co-worker relationships more when they worked in open-plan and large offices than in shared, private, and small ones.

\section{Noise Annoyance, Subjective and Environmental Characteristics}

No differences in noise annoyance were found with respect to gender, as both male and female respondents gave, on average, not statistically significantly different ratings to the question on noise annoyance (Q1) under the different remote working settings (i.e., separate, shared, outdoor, other, mix of environments). This result is coherent with the findings of $\mathrm{Di}$ Blasio et al. (2019) who did not assess any statistically significant difference in gender when analyzing noise annoyance in shared rooms, to which the remote working settings of separate or shared environments at home can be compared.

As far as the analysis of age-range in relation to noise annoyance is concerned, working in a separate environment of the house was related to a higher degree of perceived noise annoyance for younger respondents. Working in a shared environment, instead, was related to the highest higher degree of perceived noise annoyance in the 36-50 years of age range. These outcomes seem to be in contradiction to other studies, in which a dependency of annoyance and age was assessed with elder workers being more annoyed by noise than younger (Pierrette et al., 2015; Di Blasio et al., 2019). However, the difference in the results can be due to the different sizes of the participant samples considered in the studies and also to the fact that the working environment is not exactly the same, so some comparisons can be done but not all the results can be matched between situations. Indeed, the outcome of the present study related to noise annoyance for workers in shared environments of the house, which revealed a greater annoyance in subjects of 36-50 years, corresponds to a situation in which the number of people and even of children in the whole home is higher, thus noise annoyance can depend on other psychological aspects too (e.g., the need of answering to the other premises and a major request to switch between cognitive and practical tasks).
Furthermore, this outcome is in agreement with Van Gerven et al. (2009) who found middle-aged subjects-peaking around 45 years of age- to be the most annoyed by noise in a transversal study across all the lifespan, regardless of the noise exposure level and of the individually perceived noise sensitivity.

The professional sector to which respondents belonged to revealed differences, again, when workers performed the remote activity in separate or shared environments of the house. In particular, "researchers" and workers in the field of "creative, design and architecture" were mostly annoyed by noise in separate and shared environments, respectively. Overall, it is not possible to establish a comparison with other studies, as different work categories were either used or group sizes were available. Therefore, future works should establish more similar categories related to the professional sector, maybe introducing a clustering related to the predominant cognitive task carried out. As an example, anthropic noise was found to annoy workers performing mathematical tasks by Logie and Baddeley (1987). Associating, for instance, engineers and technicians with such a cognitive task could help in finding more evident trends.

In relation to the location of the cities where remote working was performed, respondents from northern Italy were most annoyed by noise if they worked from a separate environment of the house. On the opposite, when considering a shared environment of the house, workers were most annoyed by noise if they were in southern Italy. This outcome needs to be deepened, maybe performing a repeated assessment via questionnaire in different periods of the year to understand if weather issues influence this answer or if such perception is recurrent based on location.

Last, considering the number of people in the working environment and in the overall living environment, the same significant trend was found, as expected: the more people were present either in the environment or in the whole house, the more respondents were annoyed by noise.

\section{Occupants' Behavior}

It is worth giving an insight into the outcomes related to the potential involvement of occupants to increase well-being and reduce noise annoyance under remote working settings. To this aim, Q7 was designed to understand whether a worker had an inclination to activate personal strategies to reduce noise annoyance. Less than one-fifth of the respondents do not adopt any strategy. The $14 \%$ of respondents use technological tools to mask or cancel noise (e.g., wearing headphones), whereas the $12 \%$ of respondents actively ask other mates to reduce their voice level to keep high focus on the working task. The majority of responses was interestingly concentrated on "use adaptive behaviors" to find the most adequate soundscape to perform working (e.g., change room, switch between working tasks, interact with the environment to change its soundscape); therefore, remote workers are interested in being active part of the occupant-environment relationship to solve a problem and increase the sense of well-being in it. A similar result was obtained by Di Blasio et al. (2019) who found that workers from shared offices, which are almost comparable for size and occupation to the shared environments of the house, reported to adopt active strategies to reduce noise annoyance. 


\section{STRENGTHS AND LIMITATIONS OF THE STUDY}

A strength related to the present work is its capability of giving insights on a real condition in which a great portion of workers is asked to perform nowadays. Literature has focused on the understanding of the perception of the physical office environment in terms of air quality, thermal, visual, and acoustic comfort, even providing practitioners and researchers with important information on how to optimize the offices' design. This emergency, however, gives a good opportunity to ameliorate the design of indoor environments too, both in terms of sound insulation of buildings (Andargie et al., 2021) and in terms of indoor soundscapes, to support both living and working premises. In light of this latter aspect, there are very recent studies such as the one of Torresin et al. (2020a) that define some initial discussions that can be integrated with the present outcomes to build a perceptual, multisensory, and well-being-oriented design paradigm.

A main drawback of the study is related to the adoption of a negative connotation of noise as a criterion at the base of the questionnaire. The reason for this was related to the willing of extending outcomes from a similar study and to making the obtained ones as comparable as possible with the literature available. In the next future, however, a shift in the paradigm to an approach oriented on the indoor soundscape assessment will be foreseen, in order to account for the positive effects of the sound environment on the working activity as well as on perceived wellbeing. Then, another limitation of the present work relates to the little possibility of comparing its outcomes with other similar studies, as the unique condition related to the COVID-19 pandemic has taken workers to change their everyday life in a fast way and like never in history. Therefore, the main comparisons of the present study concern outcomes from investigations on offices and thus differences can still be found, or some results are difficult to be explained in depth. To this aim, it would be interesting to perform further investigations applying the same methodology that relies on online questionnaires provision to 1) increase the database of responses, 2) corroborate obtained outcomes, and 3) understand possible further changes in the occupants' subjective perception and behavior during a remote working setting that follows the emergency of one of the first pandemic periods in March-May 2020.

\section{CONCLUSION}

The aim of the present study was twofold: 1) to investigate on the effects of noise on the perceived annoyance, productivity, mental health, and well-being; and 2) to assess the relationship between noise annoyance, subjective and environmental characteristics. To this aim an online questionnaire has been administered to more than 1,934 people.

Although some of the outcomes of the present work could be expected, it is worth putting in light some aspects that should be taken into account to the aim of supporting a holistic design of home environments that are, nowadays, no longer only living but also working spaces. Indeed, as remote working seems to persist in time, results will contribute to understand the extent to which working from home can be supported by the indoor soundscape.

First, noise annoyance affects work productivity, mental health, and well-being not only in office settings but also in remote working settings, that is, when workers perform their activity from home. In particular, sharing a room-regardless of its dimensions-brings to a higher degree of perceived noise annoyance with respect to working from a separate environment in the house. Having a positive soundscape at home is thus a growing need to support several premises in one's everyday life.

Second, subjective characteristics must be taken into account when investigating the extent to which noise annoys the working activity from home. Different outcomes, in fact, were found in relation to the location of the city of remote working, as well as in relation to the age of the respondents. Further studies should better categorize respondents based on the typology of the performed working tasks (e.g., linguistic/humanistic, mathematical, technical) rather than on their specific professional sector to have a more robust clustering of the acquired data.

Third, a design approach-or practical suggestions-introducing proper spaces to be used during the remote working hours is necessary. This can be done, where possible, designing separate rooms in the house to this aim. However, when this is not possible, it would be worth integrating specific sound shields to give a greater separation of the workstation from the rest of the shared environment.

Fourth, occupant's behavior and attitude should be considered to define the ability of a built environment typically used for living, to support the intense and prolonged working activity too. This study highlighted the active behavior that workers adopt to ameliorate the soundscape of their remote working environment. The abovementioned brand-new design approach should then be supported through an integrated participatory practice that actively engages workers.

\section{DATA AVAILABILITY STATEMENT}

The raw data supporting the conclusions of this article will be made available by the authors, without undue reservation.

\section{ETHICS STATEMENT}

Ethical approval was not provided for this study on human participants because the material used in this study, consisting in the online administration of an anonymous questionnaire, was approved by the Ethic Committee of Politecnico di Torino in January 2019 for a former investigation performed and published by the same authors. In the context of the spreading of the COVID-19 pandemic in May 2020, the authors used such material and received an approval from the management area of each company involved for the questionnaires' administration. Written informed consent for participation was not required for this study in accordance with the national legislation and the institutional requirements. 


\section{AUTHOR CONTRIBUTIONS}

GEP, SDB, LS, and AA contributed in the conceptualization of the study, designed and developed the questionnaire, defined the formal analysis; SDB managed the diffusion of the questionnaire and collected data; GEP applied the formal analysis and wrote the manuscript; LS and AA reviewed the article drafts; AA supervised the research activity. All the

\section{REFERENCES}

Acoucité (2020). Soundscape and Noise Observatory of Greater Lyon, Lockdown during COVID-19 Pandemic: Impact on Sound Environment. Summary Report June 11th.

Aletta, F., Brinchi, S., Carrese, S., Gemma, A., Guattari, C., Mannini, L., et al. (2020a). Analysing Urban Traffic Volumes and Mapping Noise Emissions in Rome (Italy) in the Context of Containment Measures for the COVID-19 Disease. Noise Mapp. 7, 114-122. doi:10.1515/noise-2020-0010

Aletta, F., Oberman, T., Mitchell, A., Tong, H., and Kang, J. (2020b). Assessing the Changing Urban Sound Environment during the COVID-19 Lockdown Period Using Short-Term Acoustic Measurements. Noise Mapp. 7, 123-134. doi:10.1515/ noise-2020-0011

Aletta, F., Van Renterghem, T., and Botteldooren, D. (2018). Influence of Personal Factors on Sound Perception and Overall Experience in Urban green Areas. A Case Study of a Cycling Path Highly Exposed to Road Traffic Noise. Ijerph 15 (1118), 1-17. doi:10.3390/ijerph15061118

Amerio, A., Brambilla, A., Morganti, A., Aguglia, A., Bianchi, D., Santi, F., et al. (2020). COVID-19 Lockdown: Housing Built Environment's Effects on Mental Health. Ijerph 17 (5973), 1-10. doi:10.3390/ijerph17165973

Andargie, M. S., Touchie, M., and O'Brien, W. (2021). Case Study: A Survey of Perceived Noise in Canadian Multi-Unit Residential Buildings to Study LongTerm Implications for Widespread Teleworking. Building Acoust., 1351010X2199374. in press. doi:10.1177/1351010X21993742

Banbury, S., and Berry, D. (2005). Office Noise and Employee Concentration: Identifying Causes of Disruption and Potential Improvements. Ergonomics 48, 25-37. doi:10.1080/00140130412331311390

Barbuto, A., Gilliland, A., Peebles, R., Rossi, N., and Shrout, T. (2020). Telecommuting: Smarter Workplaces. Available at: http://hdl.handle.net/ 1811/91648 (accessed 17 June 2020)

Bartalucci, C., Borchi, F., and Carfagni, M. (2020). Noise Monitoring in Monza (Italy) during COVID-19 Pandemic by Means of the Smart Network of Sensors Developed in the LIFE MONZA Project. Noise Mapp. 7, 199-211. doi:10.1515/ noise-2020-0017

Brennan, A., Chugh, J. S., and Kline, T. (2002). Traditional versus Open Office Design. Environ. Behav. 34, 279-299. doi:10.1177/0013916502034003001

Carboni, O. A., and Russu, P. (2018). Measuring and Forecasting Regional Environmental and Economic Efficiency in Italy. Appl. Econ. 50, 335-353. doi:10.1080/00036846.2017.1313954

Colle, H. A., and Welsh, A. (1976). Acoustic Masking in Primary Memory. J. Verbal Learn. Verbal Behav. 15, 17-31. doi:10.1016/S0022-5371(76)90003-7

Danielsson, C. B. (2005). Office Environment, Health \& Job Satisfaction. An Explorative Study of Design's Influence. Stockholm, Sweden: School of ArchitectureKTH Royal Institute of Technology.

Di Blasio, S., Shtrepi, L., Puglisi, G., and Astolfi, A. (2019). A Cross-Sectional Survey on the Impact of Irrelevant Speech Noise on Annoyance, Mental Health and Well-Being, Performance and Occupants' Behavior in Shared and OpenPlan Offices. Ijerph 16 (280), 1-17. doi:10.3390/ijerph16020280

D’Orazio, D., Rossi, E., de Salvio, D., and Garai, M. (2019). "Measuring and Identifying Background Noises in Offices during Work Hours," in Proceedings of the 23rd International Congress on Acoustics: Integrating the 4th EAA Euroregio, 9. Aachen: Aachen, September.

D'Orazio, D., Rossi, E., and Garai, M. (2018). Comparison of Different In Situ Measurements Techniques of Intelligibility in an Open-Plan Office. Building Acoust. 25 (2), 111-122. doi:10.1177/1351010X18776431 authors have read and agreed to the published version of the manuscript.

\section{ACKNOWLEDGMENTS}

The kind collaboration of the management area of each company and the participation of the workers have made this work possible.

Evans, G. W., and Johnson, D. (2000). Stress and Open-Office Noise. J. Appl. Psychol. 85, 779-783. doi:10.1037/0021-9010.85.5.779

Haapakangas, A., Hongisto, V., Hyönä, J., Kokko, J., and Keränen, J. (2014). Effects of Unattended Speech on Performance and Subjective Distraction: the Role of Acoustic Design in Open-Plan Offices. Appl. Acoust. 86, 1-16. doi:10.1016/ j.apacoust.2014.04.018

Hongisto, V., Virjonen, P., and Keränen, J. (2007). "Determination of Acoustic Conditions in Open Offices and Suggestions for Acoustic Classification," in Proceedings of the 19th International Congress on Acoustics. Madrid: September 2, 7.

Hornberg, J., Haselhoff, T., Lawrence, B. T., Fischer, J. L., Ahmed, S., Gruehn, D., et al. (2021). Impact of the COVID-19 Lockdown Measures on Noise Levels in Urban Areas-A Pre/during Comparison of Long-Term Sound Pressure Measurements in the Ruhr Area, Germany. Ijerph 18 (4653), 1-16. doi:10.3390/ijerph18094653

ISTAT-Istituto Nazionale di Statistica (2020). Situazione e prospettive delle imprese nell'emergenza sanitaria COVID-19. Available at: https://www.istat. it/it/files//2020/12/REPORT-COVID-IMPRESE-DICEMBRE.pdf (accessed 3 February 2021)

Jahncke, H., Hygge, S., Halin, N., Green, A. M., and Dimberg, K. (2011). Open-plan Office Noise: Cognitive Performance and Restoration. J. Environ. Psychol. 31, 373-382. doi:10.1016/j.jenvp.2011.07.002

Kaarlela-Tuomaala, A., Helenius, R., Keskinen, E., and Hongisto, V. (2009). Effects of Acoustic Environment on Work in Private Office Rooms and Open-Plan Offices - Longitudinal Study during Relocation. Ergonomics 52, 1423-1444. doi:10.1080/00140130903154579

Logie, R. H., and Baddeley, A. D. (1987). Cognitive Processes in Counting. J. Exp. Psychol. Learn. Mem. Cogn. 13, 310-326. doi:10.1037/0278-7393.13.2.310

Manzano, J. V., Pastor, J. A. A., Quesada, R. G., Aletta, F., Oberman, T., Mitchell, A., et al. (2021). The "sound of Silence" in Granada during the COVID-19 Lockdown. Noise Mapp. 8 (1), 16-31. doi:10.1515/noise-2021-0002

McDowell, C. P., Herring, M. P., Lansing, J., Brower, C., and Meyer, J. D. (2020). Working from home and Job Loss Due to the COVID-19 Pandemic Are Associated with Greater Time in Sedentary Behaviors. Front. Public Health 8, 597619. doi:10.3389/fpubh.2020.597619

Molino, M., Cortese, C., and Ghislieri, C. (2019). Unsustainable Working Conditions: the Association of Destructive Leadership, Use of Technology, and Workload with Workaholism and Exhaustion. Sustainability 11, 1-14. doi:10.3390/su11020446

Nulty, D. D. (2008). The Adequacy of Response Rates to Online and Paper Surveys: What Can Be Done? Assess. Eval. Higher Edu. 33, 301-314. doi:10.1080/ 02602930701293231

Pejtersen, J., Allermann, L., Kristensen, T. S., and Poulsen, O. M. (2006). Indoor Climate, Psychosocial Work Environment and Symptoms in Open-Plan Offices. Indoor Air 16, 392-401. doi:10.1111/j.1600-0668.2006.00444.x

Pierrette, M., Parizet, E., Chevret, P., and Chatillon, J. (2015). Noise Effect on comfort in Open-Space Offices: Development of an Assessment Questionnaire. Ergonomics 58, 96-106. doi:10.1080/00140139.2014.961972

Sakagami, K. (2020). How Did the 'state of Emergency' Declaration in Japan Due to the COVID-19 Pandemic Affect the Acoustic Environment in a rather Quiet Residential Area? Ucloe 2 (1), 06. doi:10.14324/111.444/ucloe.000009

Salanova, M., Llorens, S., and Cifre, E. (2013). The Dark Side of Technologies: Technostress Among Users of Information and Communication Technologies. Int. J. Psychol. 48, 422-436. doi:10.1080/00207594.2012.680460

Schlittmeier, S. J., and Liebl, A. (2015). The Effects of Intelligible Irrelevant Background Speech in Offices - Cognitive Disturbance, Annoyance, and Solutions. Facilities 33, 61-75. doi:10.1108/F-05-2013-0036 
Senese, V. P., Ruotolo, F., Ruggiero, G., and Iachini, T. (2012). The Italian Version of the Weinstein Noise Sensitivity Scale. Eur. J. Psychol. Assess. 28 (2), 118-124. doi:10.1027/1015-5759/a000099

Şentop Dümen, A., and Şaher, K. (2020). Noise Annoyance during Covid19 Lockdown: A Research of Public Opinion before and during the Pandemic. J. Acoust. Soc. Am. 148 (6), 3489-3496. doi:10.1121/ 10.0002667

Sigel, S., and Castellan, N. J. (1988). Non Parametric Statistics for the Behavioral Sciences. 2nd ed. New York, NY, USA: McGraw-Hill, 116-126. 184-194, ISBN13: 978-0070573574, ISBN-10: 0070573573.

Spagnoli, P., Molino, M., Molinaro, D., Giancaspro, M. L., Manuti, A., and Ghislieri, C. (2020). Workaholism and Technostress during the COVID-19 Emergency: the Crucial Role of the Leaders on Remote Working. Front. Psychol. 11, 620310. doi:10.3389/fpsyg.2020.620310

Stansfeld, S., Clark, C., Smuk, M., Gallacher, J., and Babisch, W. (2021). Road Traffic Noise, Noise Sensitivity, Noise Annoyance, Psychological and Physical Health and Mortality. Environ. Health 20 (1), 1-24. doi:10.1186/s12940-02100720-3

Tarafdar, M., Tu, Q., and Ragu-Nathan, T. S. (2010). Impact of Technostress on End-User Satisfaction and Performance. J. Manage. Inf. Syst. 27, 303-334. doi:10.2753/MIS0742-1222270311

Thulin, E., Vilhelmson, B., and Johansson, M. (2020). New Telework, Time Pressure, and Time Use Control in Everyday Life. Sustainability 11, 3067. doi:10.3390/su11113067

Torresin, S., Albatici, R., Aletta, F., Babich, F., Oberman, T., Siboni, S., et al. (2020a). Indoor Soundscape Assessment: A Principal Components Model of Acoustic Perception in Residential Buildings. Building Environ. 182 (107152), 1-16. doi:10.1016/j.buildenv.2020.107152

Torresin, S., Albatici, R., Aletta, F., Babich, F., Oberman, T., Stawinoga, A. E., et al. (2021). Indoor Soundscapes at home during the COVID-19 Lockdown in London - Part I: Associations between the Perception of the Acoustic Environment, Occupantś Activity and Well-Being. Appl. Acoust., 183. Applied Acoustics, 108305. in press. doi:10.1016/j.apacoust.2021.108305
Torresin, S., Aletta, F., Babich, F., Bourdeau, E., Harvie-Clark, J., Kang, J., et al. (2020b). Acoustics for Supportive and Healthy Buildings: Emerging Themes on Indoor Soundscape Research. Sustainability 12, 6054. doi: $10.3390 /$ su12156054

Van Gerven, P. W. M., Vos, H., Van Boxtel, M. P. J., Janssen, S. A., and Miedema, H. M. E. (2009). Annoyance from Environmental Noise across the Lifespan. The J. Acoust. Soc. America 126 (1), 187-194. doi:10.1121/ 1.3147510

WHO-World Health Organization (2000). Mental Health and Work: Impact, Issues and Good Practices. Available at: https://apps.who.int/iris/bitstream/ handle/10665/42346/WHO_MSD_MPS_00.2.pdf?sequence $=12$ \&isAllowed $=y$ (accessed 20 March 2021).

WHO-World Health Organization (2007). Large Analysis and Review of European Housing and Health Status. Available at: https://www.euro.who.int/_data/ assets/pdf_file/0007/107476/lares_result.pdf (accessed 3 February 2021).

Conflict of Interest: The authors declare that the research was conducted in the absence of any commercial or financial relationships that could be construed as a potential conflict of interest.

Publisher's Note: All claims expressed in this article are solely those of the authors and do not necessarily represent those of their affiliated organizations, or those of the publisher, the editors and the reviewers. Any product that may be evaluated in this article, or claim that may be made by its manufacturer, is not guaranteed or endorsed by the publisher.

Copyright (C) 2021 Puglisi, Di Blasio, Shtrepi and Astolfi. This is an open-access article distributed under the terms of the Creative Commons Attribution License (CC BY). The use, distribution or reproduction in other forums is permitted, provided the original author(s) and the copyright owner(s) are credited and that the original publication in this journal is cited, in accordance with accepted academic practice. No use, distribution or reproduction is permitted which does not comply with these terms. 